\title{
LA ACCESORIEDAD DE LAS GARANTÍAS EN EL DERECHO ROMANO. ¿SON LAS ACTUALES GARANTÍAS INDEPENDIENTES FIGURAS DE NUEVO CUÑO?
}

\author{
[The Accessory Character of Guarantees in Roman Law. Are the Present \\ Independent Guarantees Newly Formed Legal Concepts?]
}

\author{
Ana M. Rodríguez GonZÁLEZ* \\ Universidad Carlos III de Madrid, España
}

\begin{abstract}
RESUMEN
El artículo comienza por analizar el elemento jurídico de la accesoriedad en las obligaciones de garantía del Derecho romano. Tras el análisis de los textos se llega a la conclusión de que el término accesoriedad no fue un concepto abstracto identificador, per se, de ninguno de los negocios de garantía utilizados, y de que la fideiussio tampoco fue concebida como modelo típico de garantía accesoria. En segundo lugar, el artículo destaca que el Derecho romano conoció ya negocios jurídicos similares a las actuales garantías independientes o abstractas, como fueron el receptum argentarii clásico, la cathará antiphónesis bizantina o la aún desconocida práctica de constituere indefense. A partir de la constatación de estos dos extremos en las fuentes, el artículo propone finalmente una
\end{abstract}

\begin{abstract}
This work proposes a reflection on the historical grounds of the current Independent Guaranties. On the one hand the work calls into question their recent origin and cast doubt that their etiology is tied on contemporary international trading requests. It can therefore be concluded that Independent Guaranties, rather than be born ex novo, they are elements of our legal tradition, receiving the baton of some other Classic Roman and Justinianean Law similar affairs. On the other hand, the work questions the understanding of suretyship as a typical guarantee contract model. The work concludes that this conception of suretyship is, by contrast, much more recent, as it comes from European phenomenon of Civil Law codification. The verification of these two
\end{abstract}

RECiBIDO el 11 de agosto de 2017 y ACEPTADO el 6 de abril de 2018

* Doctora en Derecho, Universidad Carlos III de Madrid, España; Profesora de Derecho Romano en la Facultad de Ciencias Sociales y Jurídicas de la Universidad Carlos III de Madrid. Dirección postal: Calle Madrid 126, 28903 Getafe (Madrid), España. Correo electrónico: anamaria.rodriguez@uc3m.es. ORCID 0000-0002-7287-1847. 
reflexión sobre los presupuestos históricojurídicos de las modernas garantías independientes, cuestionando la afirmación común de que éstas han sido desconocidas hasta el pasado siglo, y confirmando, por otro lado, que estos negocios tienen una naturaleza jurídica propia, distinta de la de la fianza.

\section{Palabras Clave}

Garantías independientes - fianza - fideiussio - receptum argentarii - cathará antiphónesis - Derecho romano - Derecho civil español - Derecho mercantil español. statements leads us to consider Independent Guaranties as a specific contract different from the suretyship concept, adding value on their long term rooting in the Roman Law tradition.

KEYwORDS
Independent guarantees - bail -
fideiussio - receptum argentarii - cathará
antiphónesis - Roman law - Spanish civil
law - Spanish commercial law.

\section{LA ACCESORIEDAD DE LAS GARANTÍAS ROMANAS}

\section{Las garantías personales en el Derecho romano anterior a la compilación} justinianea

Es sabido que no existió en el Derecho romano un t i p o b á s i c o de garantía definido e individualizado por su carácter accesorio. El Derecho romano no reguló de forma unitaria las garantías de las obligaciones ${ }^{1}$ y tampoco configuró un t i p o g e n e ral de garantía personal como el que algunos reconocen hoy en la fianza del código civil español, o en los equivalentes cautionement, fideiussione o Bürgschaft de otros códigos civiles europeos ${ }^{2}$. La necesidad de reforzar la posición del acreedor para aumentar sus expectativas de satisfacción del crédito fue atendida en la experiencia jurídica romana mediante el recurso a diversidad de mecanismos. Las fuentes dan noticia de antiguos garantes como los vades y praedes $^{3}$, y de otros más recientes como los sponsores, fidepromissores y fideiussores;

1 Talamanca, Mario, voz Fidesiussione (Storia), en ED., XVII, (Milano, 1958), p. 322; DE Martino, Francesco, voz Fidesiussione (Derecho romano), en NNDI, VII, p. 272; De MarTiNo, Francesco, Studi sulle garanzie personali, II, Intorno alla Sotria della Sponsio (Napoli, 1938), ahora en D'Ippolito, Federico (ed.), Diritto, economia e Società nel mondo romano (Napoli, 1995), I, p. 224; BIONDI, Biondo, Sponsio e Stipulatio. Divagazioni intorno alla storia del contratto, dell'obligatio, delle garanzie personali, en BIDR., 65 (1962), p. 105 ss.; Zoz, Gabriella, Brevi considerazioni sull'assunzione di responsabilità per debito altrui (Trieste, 2011), p. 4.

2 Véase Chianale, Angelo, voz Fideiussione in Diritto comparato, en Digesto delle Discipline Privatistiche. Sezione Civile (Torino, 1992), VIII, pp. 275 s.

${ }^{3}$ Los vades actuaban como garantes de la comparecencia del demandado-acusado en el seno de un proceso civil-criminal (Gai. 4,184-185). Los praedes, relacionados inicialmente también con el proceso, pues garantizaban la eventual restitución de la cosa litigiosa por parte del poseedor interino hasta la sentencia judicial (Gai. 4,16), asumieron también otras funciones como la de asegurar la ejecución de los contratos de obras públicas adjudicadas a particulares. Ambos sujetos-vades y praedes-garantizaban un hecho debido por otra persona y se hacían responsables -únicos responsables- del cumplimiento del mismo. Son los dos tipos de garantes más antiguos y desaparecieron en la época clásica. Véase FrEzZA, Paolo, Le garanzie dell obbligazioni. Corso di Diritto romano, I. Le garanzie personali (Milano, 1962), pp. 9 ss. Por su parcial desconocimiento, 
pero también se utilizaron con finalidad de garantía el mandatum (pecuniae credendae), el constitutum debiti (alieni) o el receptum argentarii.

a) Sponsio, fidepromissio, fideiussio. El término accessio efectivamente aparece en los textos que hacen referencia a estas tres formas de garantía promisoria ${ }^{4} \mathrm{y}$ alude, en primer lugar, a la acción de añadir o incorporar una obligación a otra ya existente ${ }^{5}$. Este es el sentido que tienen las palabras de Gayo (Gai. 3,119 y 3, 119a) cuando diferencia la sponsio y la fidepromissio de la fideiussio, diciendo que las dos primeras sólo pueden sumarse (accedere) a una stipulatio previa, esto es, a una obligatio nacida de promesa verbal solemne; mientras que la tercera, la fideiussio, podía hacerlo (adici potest) respecto de cualquier tipo de obligación ${ }^{6}$. El jurista, en el seno de esta contraposición entre una y otra figura promisoria, fundamenta en esta accesoriedad la exigencia de que la obligación principal sea una obligación válida. Pero mientras la sponsio y la fidepromissio requirieron una mera stipulatio previa formalmente válida ${ }^{7}$ (aunque resultara ineficaz y no diera lugar

por su desaparición temprana y por el ámbito restringido en el que parece que actuaron, no se tendrán aquí en mayor consideración, pero es interesante mencionar que en ellos no podía caber relación de accesoriedad entre la obligación garantizada y la responsabilidad asumida por el garante. Talamanca subraya el carácter de heterogarantes de vades y praedes, que actuaban para asegurar al acreedor la consecución de un resultado objetivo. Véase TALAMANCA, Mario, voz Fideiussione, cit. (n. 1), p. 322; ÉL MISMO, L'accessorietà della garenzia fideiussoria. Dall'esperienza romana alle codificazioni moderne (considerazioni finali), en VACCA, Letizia (ed.), La garanzia nella prospettiva storico-comparatistica, V Congresso Internazionale ARISTEC, Salisburgo, 13-15 settembre 2001 (Torino, 2003), p. 151.

${ }^{4}$ Las tres formas son consideradas por Gayo como contratos verbales que se perfeccionan por el intercambio de pregunta y respuesta entre acreedor y deudor (Gai. 3,92: "Verbis obligatio fit ex interrogatione et responsione, uelut DARI SPONDES? SPONDEO, DABIS? DABO, PROMITTIS? PROMITTO, FIDEPROMITTIS? FIDEPROMITTO, FIDEIVBES? FIDEIVBEO, FACIES? FACIAM). No obstante, confróntese D'ORs, Álvaro, Derecho privado romano (10 a edición, Pamplona, 2004), \$446, quien opina que la fideiussio, en rigor, no era una promissio, sino que se trataba de autorizar o avalar por la propia fides. De las tres formas, la sponsio parece haber sido la garantía más antigua, pues ella se refiere en exclusiva la ley Publilia, más antigua que la ley Apuleia, que ya alude a las dos formas de garantía. Véase TORRent RuIz, Armando, Accesoriedad de las garantías personales y 'beneficium excussionis', en GARCía SÁNCHEZ, Justo, De la Rosa Díaz, Pelayo y Torrent RuIz, Armando (eds.), Estudios Jurídicos 'in memoriam' del Profesor Alfredo Calonge (Salamanca, 2002), II, pp. 1036 ss.; TalamanCA, Mario, voz Fidesiussione, cit. (n. 1), p. 326, n. 27.

5 Véase, por ejemplo, D. 46,1,6 (Ulp. 47 ad Sab): adicere fideiussionem. Véase también DE Martino, Francesco, Studi sulle garanzie personali, cit. (n. 1), II, p.17.

${ }^{6}$ Gai. 3,119: "Nam illi (sponsores et fidepromissores) nullis obligationibus accedere possunt nisi verborum"; Gai. 3,119a: "Fideiussor uero omnibus obligationibus [...] adici potest". Véase también D. 46,1,1 (Ulp. 39 ad Sab): "Omni obligationi fideiussor accedere potest"; D. 46,1,8,1 (Ulp.47 ad Sab): "Praeterea sciendum est fideiussorem adhiberi omni obligationi posse, sive re sive verbis sive consensus".

${ }^{7}$ No se exigió que la estipulación resultara eficaz: se admitió el caso de la estipulación realizada por un pupilo o una mujer sin la intervención del tutor, o la promesa para después de la muerte. Véase Gai, 3,119 y confróntese con D. 46,1,26 (Ulp. 11 ed). Algunos autores califican la accesoriedad de la sponsio y la fidepromissio como meramente estructural o formal. Véase TalamancA, Mario, L'accessorietà della garanzia, cit. (n. 3) p. 153; DE MARTino, Francesco, voz 
a una deuda exigible), la fideiussio, en cambio, requirió una obligación principal válida y eficaz, fuera ésta civil, honoraria, presente o futura, o, incluso, natural y derivada de un delito ${ }^{8}$. En atención a este razonamiento, la accesión aludida por Gayo suele calificarse por los autores modernos como una accesión genética, para subrayar el hecho de que la dependencia de la obligación de garantía respecto a la obligación principal alude al momento de su nacimiento?

Gayo relaciona también la accesoriedad con la exigencia de que la obligación del garante no resulte más gravosa que la que asume el deudor principal: "nec plus in accessione esse potest quam in principali reo" ${ }^{\prime \prime}$. Este mismo aspecto es confirmado también por Juliano, Paulo y Ulpiano, quienes precisan, además, que el fideiussor puede garantizar bajo término o condición una deuda pura, pero no al revés ${ }^{11}$. Sin embargo, hay que decir que el fundamento de tal limitación de la obligación de garantía, que no puede establecerse in duriorem causa (en condiciones más gravosas que las de la obligación principal), se explica porque el garante asume idem, lo mismo que debe el deudor principal ${ }^{12}$.

Más allá de las referencias explícitas de las fuentes a una relación de accessio entre la obligación de garantía y la principal con el significado descrito, puede prestarse atención a si se generan o no efectos semejantes a los que suelen asociarse con el concepto moderno de accesoriedad, que podrían resumirse de este modo: necesidad

Fidesiussione, cit. (n. 1), p. 272. Cfr. SEGRÉ, Gino, In materia di garanzie personali, en Bollettino dell'Istituto di diritto romano 42 (N.S.1), ahora en Scritti vari di diritto romano (Torino, 1942), pp. 482 ss.

${ }^{8}$ Gai. 3,119a; D. 46,1,8,2 (Ulp.47 ad Sab); D. 46,1,6,2 (Ulp.47 ad Sab).; D. 46,1,8,5 (Ulp. 27 ad Sab), y confróntense con D. 46,1,70,5 (Gai. 1 de verb. obligat.).

9 Véase Talamanca, Mario, voz Fideiussione, cit. (n. 1), p. 331; ÉL Mismo, L'accessorietà della garanzia, cit. (n. 3) p. 153; Mannino destaca cómo la exclusión de las garantías fideiussorias ex alia causa se explica por la exigencia de una identidad del debitum del deudor principal y del garante bajo el aspecto genético. Véase MANNINO, Vincenzo, Fideiussione e accessorietà, en VACCA, Letizia, La garanzia nella prospettiva storico-comparatistica, cit. (n. 3), p. 64.

${ }^{10}$ Gai. 3,126: "In eo quoque iure par condicio est omnium, sponsorum, fidepromissorum, fideiussorum, quod ita obligari non possunt, ut plus debeant, quam debet is, pro quo obligantur. At ex diuerso, ut minus debeant, obligari possunt, sicut in adstipulatoris persona diximus; nam ut adstipulatoris, ita et horum obligatio accessio est principalis obligationis, nec plus in accessione esse potest quam in principali reo"; I.3,20,5: "Fideiussores ita obligari non possunt, ut plus debeant, quam debet is pro quo obligantur: nam eorum obligatio accessio est principalis obligationis nec plus in accessione esse potest quam in principali re. at ex diverso, ut minus debeant, obligari possunt. itaque si reus decem aureos promiserit, fideiussor in quinque recta obligatur: contra vero non potest obligari. item si ille pure promiserit, fideiussor sub condicione promittere potest: contra vero non potest. non solum enim in quantitate, sed etiam in tempore minus et plus intellegitur. plus est enim statim aliquid dare, minus est post tempus dare".

11 Nótese que la justificación del rechazo de garantías puras sobre deudas condicionadas está en que el garante asumiría una obligación in duriorem causam. Véase D. 46,1,8,7 (Ulp. 47 ad Sabinum): Illud commune est in universis, qui pro aliis obligantur, quod, si fuerint in duriorem causam adhibiti, placuit eos omnino non obligari: in leviorem plane causam accipi possunt, propter quod in minorem summam recte fideiussor accipietur. Item accepto reo pure ipse ex die vel sub condicione accipi potest: enimvero si reus sub condicione sit acceptus, fideiussor pure, non obligabitur. Véase también D. 46,1,16,1 (Iul. 53 dig); D. 46,1,34 (Paul.72 ed); y otros ejemplos en D. 46,1,8,8-11 (Ulp. 47 ad Sabinum).

12 Véase Talamanca, Mario, L'accessorietà della garanzia, cit. (n. 3), pp. 153-154. 
de validez y eficacia de la obligación garantizada para que pueda hacerse valer la garantía; las vicisitudes de la obligación garantizada (extinción total o parcial por pago u otro mecanismo de extinción de las obligaciones) afectan directamente a la garantía; el garante puede oponer al acreedor excepciones procesales derivadas de la obligación garantizada; y, por último, la obligación de garantía es siempre subsidiaria respecto de la obligación principal. En este sentido puede decirse que existen algunas coincidencias entre la fideiussio de las fuentes romanas y la fianza del código civil español. Por un lado, ya se ha mencionado, está la imposibilidad de que el fiador se obligue a más de lo que lo está el deudor principal. Además, la mora del deudor afecta en algunos casos al garante ${ }^{13}$, y se observa asimismo una tendencia a extender al fideiussor las excepciones derivadas de la obligación principal (rei cohaerentes). No obstante, hay que observar que, en el caso de las excepciones propias del deudor principal (persona cohaerentes) ${ }^{14}$ las excepciones se extienden al garante solo en algunos casos, y éstos no aparecen nunca justificados en la accesoriedad de la obligación de garantía ${ }^{15}$. A lo que hay que añadir que, a diferencia de lo que ocurre en la fianza del código civil español, no se admitió para el fideiussor el beneficium ordinis seu excussionis hasta la intervención de Justiniano en el año 535 d.C. (Nov. 4) ${ }^{16}$.

Por todo lo anterior, puede afirmarse que la sponsio, fidepromissio y fideiussio no aparecen fundadas sobre una construcción teórica de la accesoriedad que se corresponda con el concepto moderno. Las tres promesas de garantía se califican como accesorias de otra obligación (Gayo), pero el término accessio no significa

13 Véase Talamanca, Mario, voz Fideiussione, cit. (n. 1), p. 333.

14 Véase D. 44,1,7,1 (Paul. 3 ad Plautium).

15 La motivación de las decisiones de los juristas no es unívoca, y las dificultades de interpretación se agravan para nosotros por la probable alteración de algunos fragmentos que originariamente se referían a la sponsio y la fidepromissio, y que aparecen en el Digesto como relativos a la fideiussio. No obstante, cuando los prudentes deciden que el garante puede oponer al acreedor las excepciones propias del deudor, a menudo su argumento alude a los efectos contradictorios que se producirían si el deudor tuviera que pagar al fideiussor en vía de regreso, cuando habría podido defenderse ope exceptionis contra su acreedor inicial. De todos modos, los estudiosos se muestran partidarios de realizar una exégesis de textos que tenga en cuenta los intereses del caso concreto y el distinto tipo de excepción procesal del que se trate en ellos. Véase Talamanca, Mario, voz Fidesiussione, cit. (n. 1) p. 336; De Martino, Francesco, voz Fidesiussione, cit. (n. 1), p. 273; MANNINO, Vincenzo, L'estensione al garante delle eccezioni del debitore principale nel diritto romano classico (Torino, 1992).

16 El garante o garantes se colocaban respecto al acreedor en la misma posición que el deudor principal y pueden ser demandados aunque no se haya procedido antes contra el deudor principal. No obstante, véase la posibilidad de ejercitar la actio iniuriarum mencionada en D. 47,10,19 (Gai. 22 ed. Prov.). Inicialmente, ni siquiera estaba prevista la división entre los cogarantes o entre éstos y el deudor principal: en el caso de la Sponsio y fidepromissio, hasta la Lex Publiblia de sponsu no se previó acción de regreso contra cogarantes, y hasta las leyes Apuleia y Furia de sponsu el regreso contra el deudor principal; en el caso de la fideiussio, fue Adriano quien introdujo el llamado beneficium divisionis en el siglo II d.C. Suele decirse que la obligación que asumen estos garantes adpromissores es una obligación solidariamente accesoria. Véase Mannino, Vincenzo, voz Garanzie dell'obbligazione, en Digesto delle discipline privatistiche. Sezione Civile (Torino, 1992), VIII, p. 617; Torrent, Armando, Accesoriedad de las garantías personales, cit. (n. 4), pp. 1035-1048. 
necesariamente dependencia funcional total entre la obligación de garantía y la obligación principal (esto se ve con claridad en la sponsio y la fidepromissio, igualmente accesorias para Gayo, pero cuya validez depende de la existencia meramente formal de la estipulación que garantizan, siendo indiferente que la obligación principal no llegue a ser exigible). Por otra parte, tampoco los efectos de estas garantías promisorias pueden equipararse con los previstos en el código civil para la fianza, pues durante el período clásico persiste la solidaridad en lugar de la subsidiariedad del código.

A esto hay que añadir que, si la accesoriedad no fue el elemento clave sobre el que los juristas romanos construyeron la identidad o esencia de la fideiussio, lo fue aún menos en el caso de otros mecanismos de garantía. Lo veremos a continuación.

b) Mediante el mandatum pecuniae credendae un sujeto pide a otro que preste dinero a un tercero. Con ello se consigue que el prestamista se asegure el cobro de lo prestado, ya que si el mutuario no paga podrá dirigirse contra el mandante como ordenante del préstamo con la actio mandati contraria. En este caso la relación existente entre el garante y el acreedor, basada en el mandato, es independiente de la que nace del préstamo entre el acreedor y el deudor garantizado. La acción del prestamista para reclamar la devolución del mutuo -la actio creditae pecuniae - no impide el ejercicio de la actio mandati contraria en el caso de que el deudor fuera insolvente. Al contrario, la reclamación al mandante se justifica en el perjuicio sufrido por el negocio encomendado, esto es, la falta de recuperación del dinero prestado por encargo ${ }^{17}$.

c) Constitutum debiti alieni ${ }^{18}$, o constituere pro alieno debito ${ }^{19}$ (constituto de

17 Véase Guarino, Antonio, Mandatum credendi (Napoli, 1982); recientemente GonZÁLEZPalenzuela, M. Teresa, El mandatum pecuniae credendae en el Derecho romano: de instrumento para la promoción del crédito a instrumento de garantía, en Revista General de Derecho Romano, 25 (2015); una exposición general básica puede leerse en FrEZZA, Paolo, Le garanzie delle obligazioni. Corso di diritto romano I, Le garanzie personali (Padova, 1962), pp. 199 ss.

${ }_{18}$ Obra clásica y fundamental sobre el Constitutum debiti es AstuTI, Guido, Studi preliminari intorno alla promessa di pagamento I. Il costituto di debito, en Annali della Facultà giuridica dell'Università di Camerino, 11 (1937), pp. 83 ss.; y Studi intorno alla promessa di pagamento. Il Costituto di debito (Milano, 1941), II. En estas dos obras hace una exposición completa del negocio y analiza la bibliografía precedente. Más recientemente, véase RICART, Encarnació, 'Constitutum debiti' y 'solutionis causa adiectus', en Revista de la Facultad de Derecho de la Universidad Complutense, número monográfico en homenaje al Profesor D. Juan Antonio Arias Bonet, 16 (1990), pp. 241 ss.; Perfil del 'constitutum debiti', en Seminarios Complutenses de Derecho romano, 3 (1991), pp. 135 ss.; 'Constitutum debiti', en Derecho romano de obligaciones. Homenaje al Profesor José Luis Murga Gener (Madrid, 1994), pp. 695 ss.; más recientemente, VArVAro, Mario, Sulla storia dell'editto 'De pecunia constituta', en AUPA., 52 (2007-2008), pp. 327 ss.; WaELKENS, Laurent, 'Pecunia constituta', un mode de paiment du droit romain, en Memoires de la Societé pour l'Histoire du Droit et des Institutions des Anciens Pays Bourguignons, contois et romands, 65 (2008), pp. 67 ss.; CosTA, Paolo, 'Pecunia constituta': ipotesi interpretative, en SDHI., 77 (2011), pp. 129 ss.; PlatsCheK, Johannes, Das Edikt de Pecunia Constituta. Die römische Erfülungszusage und ibre Einbettung in den hellenistischen Kreditverkehr, (München, 2013).

19 Véase C. 4,18,1. 
deuda ajena o constituir por la deuda de otro) es el nombre que recibe el compromiso de pago que dirige un sujeto al acreedor de otro para hacerse responsable del abono de la cantidad debida. Inicialmente, constituere pecuniam significaba comprometerse a pagar una deuda propia ya existente (constituere pro se) ${ }^{20}$, y también en este caso puede decirse que el constitutum tenía una función de refuerzo del derecho del acreedor, pues le otorgaba la posibilidad de reclamar su crédito, no sólo con la acción derivada del contrato que les unía inicialmente (obligatio sortis), sino también con una nueva acción alternativa ${ }^{21}$, la actio de pecunia constituta. Esta acción pretoria, con fórmula in factum y condemnatio al quanti ea res est ${ }^{22}$, podía resultar más ventajosa al acreedor que la que derivaba de la llamada obligatio sortis, porque con ella el juez podía valorar el interés del demandante en el efectivo y puntual cumplimiento de esta obligación. Esto es, frente a la acción de base, (normalmente una actio certa creditae pecuniae, con una condemnatio predeterminada por el quantum de la intentio, que reflejaba la cantidad prestada y no reintegrada $)^{23}$ la acción derivada del constitutum permitía al juez una estimación del pleito teniendo en cuenta el valor de la reclamación en el momento de la litis contestatio $^{24}$. A esto había que añadir también las consecuencias que producían la sponsio y restipulatio dimidiae partis a las que podían obligarse demandado y demandante en estos juicios de constituta pecunia ${ }^{25}$; en caso de resultar condenado, la sponsio dimidiae partis del demandado le obligaría a pagar al acreedor la mitad más de lo que le hubiera sido reclamado ${ }^{26}$. Estas particularidades de la acción $e x$ constituto reforzaban, por tanto, ya desde el nacimiento del constitutum debiti propii, la efectiva satisfacción del acreedor, pero hay que decir que el negocio adquiere

${ }^{20}$ Véase C. 4,18,2,1. Astuti ha subrayado la necesidad de que el constitutum hiciera siempre referencia a un plazo dentro del cual el garante debía pagar la deuda (diem intra quem). Este plazo, una vez vencido, generaría inmediatamente la posibilidad de que el acreedor lo reclamara con la acción de pecunia constituta. Véase Astuti, Guido, Studi preliminari, cit. (n. 18), pp. 136 ss.; y Studi intorno alla promessa di pagamento, cit. (n. 18), II, pp. 25 ss.; Cfr. PlatscheK, Johannes, cit. (n. 18), pp. 145 ss.

${ }^{21}$ Véase D. 13,5,18,2 (Ulp.27 ed.): "E re autem est hic subiungere, utrum poenam contineat haec actio an rei persecutionem: et magis est, ut etiam Marcellus putat, ut rei sit persecutio". Sobre la originaria naturaleza penal de la acción, véase AsTUTI, Guido, Studi intorno alla promessa di pagamento, cit. (n. 18), II, pp. 79 ss.

${ }^{22}$ Véase D. 13,5,18,2 y 3 (Ulp.27 ed.). No obstante, los textos no nos han transmitido la condemantio de la fórmula. Sobre su posible reconstrucción, véase la bibliografía citada más adelante n. 42 .

${ }^{23}$ Se piensa que, al menos originariamente, las deudas constituidas derivaban de un préstamo de dinero, o de una estipulación de mutuo. Véase Astuti, Guido, Studi preliminari, cit. (n. 18), pp. 129 ss.; Varvaro, Mario, Sulla storia dell' editto, cit. (n. 18), pp. 332 ss.; PlatscheK, Johannes, cit. (n. 18), pp. 76 ss.

${ }^{24}$ Véase D. 13,5,14,2 (Ulp. 27 ed.), que se refiere a un constitutum mediante el que se promete prestar garantía presentando un fiador. En el caso de incumplimiento del constitutum por muerte del garante, habiendo incurrido el constituens en mora, el juez podía hacer una valoración del id quod interest.

${ }^{25}$ Gai. 4,171. Véase Astuti, Guido, Studi preliminari, cit. (n. 18), pp. 148 ss., quien no cree que se trate de una obligación sino de una facultad.

26 Véase PlatscheK, Johannes, cit. (n. 18), pp. 62 ss. 
una función de garantía más clara en la modalidad del constitutum debiti alieni, modalidad que fue cobrando con el tiempo un protagonismo mayor que la primera.

En lo que se refiere a la accesoriedad hay que decir que la existencia de la deuda asumida con el constitutum (fuera ésta propia o ajena) era un requisito esencial para la reclamación del negocio, pues la fórmula de la acción exigía que el acreedor probase el debitum constitutum ${ }^{27}$. Ahora bien, las fuentes no hacen referencia a una relación de accesión con esa obligación asegurada (obligatio sortis), al contrario, demuestran que la obligación ex constituto tenía una cierta autonomía respecto a las eventuales modificaciones que pudiera sufrir la deuda de base ${ }^{28}$. La exigencia del debitum afectaba únicamente al momento de constitución de la garantía ${ }^{29}$, por tanto, si la obligación principal dejaba después de ser exigible por causas distintas de las del pago $^{30}$, el constitutum podía reclamarse igualmente ${ }^{31}$. Este es el motivo por el que los juristas rechazaron la posibilidad de garantizar mediante constitutum las deudas sometidas a condición ${ }^{32}$, que sólo se consideraban existentes una vez que se cumplía tal condicio $^{33}$. Las limitaciones a la validez del constitutum

27 Si se atiende al tenor literal del edicto pretorio citado por Ulpiano en el libro 27 de sus comentarios (D. 13,5,1,1 Ulp. 27 ed), hay que concluir que la fórmula de la acción del constitutum debía hacer referencia expresa a la existencia del debitum. Ésta se ha reconstruido así: Si paret Numerium Negidium Aulo Agerio HS decem milia constituisse se soluturum eove nomine se satisfacturum ese neque fecisse quod constituit neque per Aulum Agerium stetisse quo minus fieret quod constitutm est, eamque pecuniam, cum constituebatur, debitam fuisse, quanti ea res est, tantam pecuniam iudex Numerium Negidium Aulo Agerio condemnato. Si non paret, absolvito. Véanse, Lenel, Otto, Das 'Edictum Perpetuum'. Ein Versuch zu seiner Wiederherstellung, (reimpresión de la $3^{\text {a }}$ edición de Leipzig de 1927, Darmstadt, 1985), pp. 247 ss.; Mantovani, Dario, Le formule del proceso privato romano per la didattica delle instituzioni di diritto romano (2a edición, Padova, 1999), p. 68; PlatscheK, Johannes, cit. (n. 18), pp. 22 ss.; Cfr. Varvaro, Mario, Sulla storia dell' editto, cit. (n. 18), pp. 333 ss.

${ }^{28}$ Véase Astuti, Guido, Studi intorno alla promessa di pagamento, cit. (n. 18), II, pp. 48 ss.

${ }^{29}$ Obsérvese que la formula probablemente hacía referencia a cum constituebatur. Véase arriba n. 42 .

${ }^{30}$ Otras causas de extinción asimilables al pago, como por ejemplo la confusión, la capitis deminutio, la datio in solutio, la compensatio. Véase, AstuTI, Guido, Studi intorno alla promessa di pagamento, cit. (n. 18), II, p. 56.

${ }_{31}$ D. 13,5,18,1 (Ulp. 27 ed): "Quod adicitur: "Eamque pecuniam cum constituebatur debitam fuisse", interpretationem pleniorem exigit. Nam primum illud efficit, ut, si quid tunc debitum fuit cum constitueretur, nunc non sit, nihilo minus teneat constitutum, quia retrorsum se actio refert. Proinde temporali actione obligatum constituendo Celsus et Iulianus scribunt teneri debere, licet post constitutum dies temporalis actionis exierit. Quare et si post tempus obligationis se soluturum constituerit, adhuc idem Iulianus putat, quoniam eo tempore constituit, quo erat obligatio, licet in id tempus quo non tenebatur". Otro ejemplo: D. 13,5,19,2 (Paul. 29 ed): "Si pater vel dominus constituerit se soluturum quod fuit in peculio, non minueretur peculium eo, quod ex ea causa obstrictus esse coeperit: et licet interierit peculium, non tamen liberatur". Astuti califica estos supuestos como casos de extinción meramente formal de la obligatio sortis. Véase AsTUTI, Guido, Studi intorno alla promessa di pagamento, cit. (n. 18), II, p. 62.

32 Véase C. 4,18,2,1 y D. 13,5,19 (Paul. 19 ed). Véase AstuTi, Guido, Studi intorno alla promessa di pagamento, cit. (n. 18), II, pp. 73 ss.; y Studi preliminari, cit. (n. 18), pp. 130 ss.; PlatscheK, Johannes, cit. (n. 18), pp. 111 ss. y 145 ss.

${ }^{33}$ No ocurría lo mismo con la obligación sometida a término, que se consideraba existente aunque no hubiese vencido el plazo establecido (Gai. 3,124), puesto que eran únicamente 
por su relación con la obligación principal no podían establecerse en orden a la prohibición de una garantía in duriorem causa, como ocurría en las promesas de garantía ya vistas (sponsio, fidepromissio y fideiussio) ${ }^{34}$. Con el constitutum no se prometía lo mismo que había prometido el deudor principal ni se asumía sobre la fides la misma obligación de otro; con el constitutum se prometía el pago de una deuda que existía en el momento de su celebración ${ }^{35}$. Salvo por este vínculo, que ha llevado a la doctrina a hablar de una accesoriedad genética del negocio de garantía, el constituens asumía un vínculo independiente ${ }^{36}$. Una independencia que es aún más pronunciada en el caso del receptum argentarii que se verá después.

\section{Transformaciones de las garantias personales en el Derecho romano justinianeo}

Puede decirse que los negocios de garantía del Derecho romano clásico fueron experimentando con el tiempo una cierta homogeneización. La tendencia uniformadora se inició ya probablemente en la época clásica, se acentuó en el período postclásico y Justiniano acabó plasmando normativamente los resultados de este proceso, y otras novedades introducidas por él, en varias constituciones imperiales.

Una primera manifestación de esta evolución es la unificación de las garantías promisorias. La sponsio y la fidepromissio desaparecieron y la fideiussio se convirtió en la única forma aludida en la compilación del Corpus Iuris Civilis ${ }^{37}$. Por otra

los efectos del negocio los que se retrasaban a un momento posterior. Sobre la discusión jurisprudencial relativa a este asunto, véase: AstuTI, Guido, Studi intorno alla promessa di pagamento, cit. (n. 18), II, pp. 63 ss.

${ }^{34}$ Astuti, Guido, Studi intorno alla promessa di pagamento, cit. (n. 18), II, pp. 48 ss. Las prohibiciones de D. 13,5,11,1 (Ulp. 27 ed); 12 (Paul 13 ed); y 13 (Paul 29 ed) me parecen fundadas en la exigencia de que la obligación ex constituto quede definida por la pecunia debita. De no ser así, no cabría la posibilidad de contraer un constitutum sin especificar el quantum, según se afirma en D. 13,5,14 (Ulp. 27 ed).

${ }^{35}$ D. 13,5,18 (Ulp. 27 ed): "Quod adicitur: 'Eamque pecuniam cum constituebatur debitam fuisse', interpretationem pleniorem exigit. Nam primum illud efficit, ut, si quid tunc debitum fuit cum constitueretur, nunc non sit, nihilo minus teneat constitutum, quia retrorsum se actio refert. Proinde temporali actione obligatum constituendo Celsus et Iulianus scribunt teneri debere, licet post constitutum dies temporalis actionis exierit. Quare et si post tempus obligationis se soluturum constituerit, adhuc idem Iulianus putat, quoniam eo tempore constituit, quo erat obligatio, licet in id tempus quo non tenebatur".

36 AstuTI, Guido, Studi intorno alla promessa di pagamento, cit. (n. 18), II, pp. 276.

37 Justiniano estableció, además, que la fideiussio debía quedar recogida por escrito para obtener una eficacia plena, pues, de otro modo, la posibilidad de reclamar al garante quedaba limitada al plazo de dos meses desde la celebración del negocio. Pasados éstos, los fideiussores podían considerarse liberados de toda obligación (C. 8,40,27 e I. 3,20,8). La constitución justinianea menciona la existencia de medidas previas pronunciadas ya en este sentido, y al parecer, la práctica de hacer constar por escrito la participación de los fideiussores como garantes estaba muy extendida. Un rescripto de Antonino (año 214) demuestra que en ocasiones se generaban dudas acerca del grado de responsabilidad de los que aparecían como firmantes de un documento de préstamo y se dudaba de si firmaban como garantes o como testigos del mutuo (C. 8,40,6). Probablemente, el proceso de registrar la fideiussio por escrito se relaciona con el proceso de decadencia de la forma verbal típica de la estipulación y su progresiva sustitución por la forma escrita. Véase, Talamanca, Mario, voz Fideiussione, cit. (n. 1), p. 338; Zoz, Gabriella, Brevi considerazioni sull'assunzione di responsabilità, cit. (n. 1), p. 14. 
parte, los efectos del mandatum pecuniae credendae se aproximaron, en la parte oriental del imperio, a los de la fideiussio. Por ejemplo, se reconoció, tanto al mandante como al fideiussor, el denominado beneficium cedendarum actionum $\mathbf{l}^{38}$; Jutiniano suprimió los efectos extintivos de la litis contestatio en la fideiussio, como ya se había previsto para el mandato ${ }^{39}$; él mismo extendió (C. 4,18,3) el benefcium divisiones, creado por Adriano para los fideiussores (Gai. 3,121; I. 3,20,4), a los mandatores ${ }^{40}$ y aquellos qui pecunias pro aliis constituunt. Y finalmente, con la medida legislativa más innovadora del régimen de las garantías personales, la Nov. $4^{41}$, introdujo el beneficium excusionis ${ }^{42}$, conjuntamente al constitutm debiti, al mandatum pecuniae credendae y a la fideiussio.

38 Con esta cesión de acciones del acreedor al garante parece haber sido ya contemplada por los juristas clásicos para la fideiussio y el mandato de crédito, aunque quizás no de forma generalizada sino atendiendo al caso concreto. Se reconoce aplicable al mandato en D. 46,1,13 (Iul.14 dig.); D. 46,3,95,10 (Pap. 28 quaest.); D. 17,1,28 (Ulp. 14 ed.). Casos de aplicación a la fideiussio se encuentran en D. 46,1,17 (Iul. 89 dig.) y D. 46,1,36 (Paul. 14 ad plaut.). Cfr. Bortolucci, Giovanii, Il mandato di crédito, en BIDR., 27 (1915), pp. 239 ss. La cesión de acciones era un mecanismo de regreso contra el deudor principal, pero, a diferencia de la actio mandati contraria, podía utilizarse también contra otros cogarantes. La cesión se conseguía recurriendo a la representación procesal del cedente, y fue posible gracias a la construcción jurisprudencial de la venditio nominis: el pago del acreedor producía inevitablemente la extinción de su derecho de crédito, sin embargo, los juristas clásicos consiguieron evitar este efecto recurriendo a la construcción jurídica de la compra de créditos. Según esta especie de ficción, se consideraba que el garante que pagaba al acreedor estaba en realidad comprando el crédito que el acreedor tenía sobre el deudor principal y podía así utilizar las acciones correspondientes contra éste. En este sentido, D. 46.1.17 (Iul. 89 dig.); D. 46.1 .36 (Paul. 14 ad Plaut.). Véase Zoz, Gabriella, Brevi considerazioni sull'assunzione di responsabilità, cit. (n. 1), pp. 23-31.

39 Se trataba de una medida ya contemplada por Diocleciano (C. 8,40,23) para los mandantes de crédito, pero Talamanca subraya el spunto classico que Justiniano habría encontrado en el régimen del concurso entre la actio certa creditae pecuniae y la actio mandati contraria. En estos casos, el efecto de la litis contestatio parece haberse discutido entre los juristas. Véase Talamanca, Mario, voz Fideiussione, cit. (n. 1), p. 339, n. 151. De todos modos, la medida justinianea relativa a la fideiussio parece consolidar una práctica ya extendida, según la cual, las partes pactaban que los fideiussores no quedaran liberados hasta el pago total y efectivo del acreedor (C. 8,40,28).

${ }^{40}$ Cfr. D. 27,7,7 (Pap. 3 resp.). La división parece haberse admitido ya antes para el caso de varios mandantes de un mismo crédito. Véase, Mannino, Vincenzo, voz Garanzie dell'obbligazione, cit. (n. 16), p. 618 n. 46. Véase también GuARINo, Antonio, Mandatum credendae, cit. (n. 17), pp. 44 ss.

${ }^{41}$ No obstante, las constituciones C. 8.40.5 (año 214) y C. 8.40.19 (años 203-304) aluden a una práctica ya existente con la que se evitaba convencionalmente la solidaridad general entre deudores y garantes.

${ }^{42}$ La expresión beneficium excusionis no fue acuñada hasta la época medieval, para indicar la prohibición de dirigirse contra los garantes antes de haberlo hecho contra el deudor principal. Sobre el sistema de prelación establecido en la Novela justinianea: véase DíAZ BAUTISTA, Antonio, Estudios sobre la banca Bizantina (negocios bancarios en la legislación de Justiniano) (Murcia, 1987), p. 154 y la reseña a todos los trabajos de este autor sobre la legislación justinianea realizada por Díaz BAUTISTA CREMAdes, Adolfo, Antonio Díaz Bautista y la legislación justinianea, en RIDROM., 12 (2014), pp. 237 ss. La constitución consolidó también el ya mencionado beneficio de cesión de acciones, que tendrá ahora la consideración de automático. Véase también BRIGUGLIO, Filippo, Fideiussoribus succurri solet (Milano, 1999), pp. 93 ss. y más recientemente 
No obstante, esta tendencia homogeneizadora de las garantías tampoco aparece cimentada en las fuentes sobre la accesoriedad. No se hace referencia a ésta cuando se alude al tratamiento conjunto de los negocios de garantía mencionados. Se observa que en la disposición justinianea con la que se extiende el beneficio de división de la fideiussio, al mandatum pecuniae credendae y al constitutum, la justificación de la medida alude genéricamente a la equidad: aequitatis enim ratio diversas species actionis excludere nullo modo debet (C. 4,18,3). Y el único rasgo que aparece mencionado expresamente en las fuentes como criterio de comparación y acercamiento entre estas tres figuras es el de constituir, todas ellas, formas de intercesión por otro sujeto ${ }^{43}$.

\section{EL RECEPTUM ARGENTARII DEL DERECHO ROMANO CLÁSICO Y SU EVOLUCIÓN POSTERIOR}

Además de los negocios con función de garantía mencionados, el Derecho romano conoció también un modo peculiar de reforzar las expectativas de cobro del acreedor, el receptum argentarii, que debe su nombre a la profesión de sus artífices, los banqueros romanos ${ }^{44}$. Mediante el receptum el banquero argentarius asumía el compromiso de pagar una deuda de un cliente, y lo hacía garantizando a su acreedor el cobro efectivo, con independencia de que la deuda resultara inexistente y de que su cliente manifestara su voluntad contraria una vez asumido el pago. Sobre este negocio jurídico existe hoy un gran desconocimiento, pues apenas se conservan fuentes que se refieran a él. Los únicos textos que aluden al receptum argentarii (rectius, acción recepticia) proceden de un momento cronológico probablemente distante del tiempo en que el negocio vivía en la práctica

Cardilli, Riccardo, Garanzie personali e obbligazione, en Scritti per Alessandro Corbino, PIRO, Isabella (ed.), (Roma, 2016), pp. 546 ss.

${ }^{43}$ Véase, por ejemplo C. 8,40,19: cuando Diocleciano se refiere en general a la solidaridad existente entre el deudor principal y los garantes, alude a éstos como los que de cualquier modo intercedieron en nombre del deudor: quocunque alio nomine pro debitore intercessisti.

44 Sobre el negocio jurídico del receptum argentarii véase: Rossello, Adolfo, Receptum argentariorum, en $A G$., 45 (1890), pp. 1-83; PARTSCH, Joseph, Der ediktale Garantievertrag durch 'receptum', en ZSS., 29 (1908), pp. 403-428; SERAFInI, Enrico, Appunti sul receptum argentariorum, en $A G$., 45 (1890), pp. 553-559; MITTEIs, Ludwig, Receptum argentarii, en 29 (1908), pp. 479-480; Wenger, Leopold, 'Receptum argentarii', en PW., vol I. A1, cols. 372379; Magdelain, André, Le consensualisme dans l'édit du preteur (Paris, 1958); PeTrucCI, Aldo, 'Mensam exercere'. Studi sull'impresa finanziaria romana (II secolo a C-metà del III secolo d.C.), (Napoli, 1991); LuCHETTI, Giovanni, Banche, banchieri e contratti bancari nella legislazione giustinianea, en BIDR., 94-95 (1991-1992), pp. 448-472; LÓPEZ AMOR, Mercedes, Receptum argentarii, receptum nautarum, cauuponum, stabulariorum, en Derecho romano de obligaciones, Homenaje al Profesor José Luis Murga Gener (Madrid, 1994), pp. 721-728; LA RosA, Franca, Il formalismo del pretore: 'constituta' e 'recepta', en Labeo 43 (1997), pp. 202-224; FASOLINO, Francesco, Sulle tecniche negoziali bancarie: il 'receptum argentarii', en Labeo 46 (2000), pp. 186188; Rodríguez González, Ana M., El 'receptum argentarii' en el Derecho romano clásico, cit. (n. 69); Carvajal, Patricio I., 'Receptum argentarii'. Nota sobre las garantías bancarias abstractas en el Derecho romano y justinianeo, en Ars boni et Aequi 1 (2005), pp. 127-148. 
del ars argentaria ${ }^{45}$. Uno de estos textos es una constitución imperial del año 531, promulgada por Justiniano, que ya se ha mencionado (C. 4,18,2); los otros dos son: un fragmento de las Instituciones del mismo emperador (I. 4,6,8), y el comentario que sobre este mismo fragmento realizó el profesor bizantino Teófilo en el seno de su paráfrasis a las Instituta ${ }^{46}$.

El receptum, tenía en común con el constitutum debiti alieni su naturaleza consensual, la libertad en la forma de celebración ${ }^{47}$ y la falta de efectos novatorios, ya que la deuda principal se mantenía junto a la obligación que nacía de ambos (por ello, cumplían ambos una función de garantía). Se diferenciaba, sin embargo, en que la eficacia del receptum, no dependía de la existencia de una previa pecunia debita, sino que generaba para el banquero una obligación que era exigible por el acreedor, aunque no existiera realmente un debitum (et si quid non fuerat debitum $)^{48}$. Por tanto, podríamos decir que, en terminología actual, el receptum argentarii era un negocio de garantía no accesorio y de carácter abstracto; es más, su abstracción se manifestaría en grado máximo ya que no admitía la oposición de ningún mecanismo de defensa, ni siquiera el de la exceptio doli, quedando como único remedio posterior al pago la reclamación de lo cobrado indebidamente con la condictio indebiti y su consiguiente carga de la prueba de lo indebido por parte del banquero demandante ${ }^{49}$.

Es cierto que la acción recepticia clásica, con la que el pretor había protegido al acreedor beneficiario del receptum de un banquero, no fue recogida en la compilación justinianea por considerarse obsoleta y desconocida en la práctica jurídica

45 Véase, C. 4,18,2 pr.: “Recepticia actione cessante, quae sollemnibus verbis composita inusitato recessit vestigio $[\ldots]$ ".

46 No obstante, tras el trabajo palingenésico de Lenel, se afirma como relativos originariamente a este negocio de garantía bancaria los siguientes fragmentos que hoy aluden al constitutum debiti: en sede De pecunia constituta, D. 13,5, 12 (Paul. 13 ed.); D. 13,5,26 (Scaev. 12 resp.); D. 13,5,27 (Ulp 14 ed.) y D. 13,5,28 (Gai. 5 ed.prov.); en sede De Fideiussoribus et mandatoribus, D. 46,1,30 (Gai. 5 ed.prov.); en sede De solutionibus et liberationibus, D. 46,3,52 (Ulp. 14 ed.) y D. 46,3,53 (Gai. 5 ed.prov.); bajo el título De edendo, D. 2,13,6,3 (Ulp. 4 ed.) y, finalmente, en sede De actio mandati vel contra, D. 17,1,28 (Ulp.14 ed.). Véase, LENEL, Otto, Palingenesia Iuris civilis, (reimpresión de la edición de Leipzig 1889, Graz, 1960); ÉL MISMO, Beiträge zur Kunde des Esdicts und der Edictcommentare, en ZSS., 1 (1881), pp. 62-71; ÉL MISMO, Das Edictum Perpetuum. Ein Versuch zu seiner Wiederherstellung (reimpresión de la 3 edición de Leipzig 1927, Aalen, 1985), p. 134 n. 5; Rossello, Adolfo, Receptum argentariorum, cit. (n. 44), pp. 5 ss.

47 Astuti, Guido, Studi intorno alla promessa di pagamento, cit. (n. 18), II, p. 284; Cfr. LA RosA, Franca, Il formalismo del pretore, cit. (n. 44), pp. 202-224.

48 C. $4,18,2$.

49 C. 4,18,2, 1: [...] cum secundum antiquam recepticiam actionem exigebatur et si quid non fuerat debitum, cum satis absurdum et tam nostris temporibus quam iustis legibus contrarium est permittere per actionem recepticiam res indebitas consequi et iterum multas proponere condiciones [...]. Sería una abstracción de mayor grado que la que se asocia con la stipulatio. En el caso de haberse celebrado una estipulación sobre una deuda inexistente o inválida, el demandado habría podido defenderse con la exceptio doli o la exceptio non numeratae pecuniae. Sobre este mecanismo, véase Carrasco García, Consuelo, Supuestos de hecho de la 'exceptio non numeratae pecuniae' en el derecho romano (Madrid, 2000). 
coetánea $^{50}$. Quizás, el desuso de este negocio bancario podría explicarse por la propia desaparición del oficio de banquero. Andreau ha llamado la atención sobre un probable eclipse de la profesión bancaria en occidente durante buena parte del siglo IV d.C., una época en la que las fuentes romanas conservadas omiten toda referencia a estos sujetos ${ }^{51}$. Tras esa posible etapa de interrupción, y coincidiendo con el retorno de las menciones de argentarii en las fuentes, la actividad bancaria habría reaparecido con una nueva fisonomía, con sujetos ocupados en algunas actividades diferentes de las del período anterior, y sometidos a una regulación jurídica en parte modificada ${ }^{52}$.

El emperador Justiniano, como se ha dicho, ordena en el año 531 que se suprima toda referencia al receptum en los textos que iban a ser compilados en el Digesto $^{53}$. Ahora bien, no cabe duda de que la práctica bancaria bizantina cono-

${ }^{50}$ A pesar de las palabras de Justiniano la doctrina se ha planteado dudas sobre la veracidad del desuso del receptum argentarii. Lenel, por ejemplo, considera que la expresión actione cessante inussitatio recessit vestigio de la constitución no hace alusión al desuso del negocio, sino de la acción procesal tal y como había sido configurada en la época clásica. Véase LenEL, Otto, Beitrage zur Kunde des Edicts, cit. (n. 46), pp. 68 y 69; LA ROSA, Franca, La pressione degli argentarii e la reforma giustinianea del constitutum debiti (C.4,18,2), en Nozione, formazione e interpretazione del diritto: dall'età romana alle esperienze moderne: ricerche dedicate al profesor Filippo Gallo (Napoli, 1997), p. 446; Collinet, Paul, Études historiques sur le droit de Justinien. Le carattere oriental de l'oenvrre legislative de Justinien et les destinées des institutions classiques en occident (Paris, 1932), I, pp. 214, 218 y 270 y ss.

${ }_{51}$ Véase ANDREAU, Jean, La vie financiére dans le monde romain. Les metiers de manieurs d'argent (IV sicle av. JC-III sicle ap. JC) (Roma, 1987), pp. 40 ss.; ÉL MISmo, Declino e norte dei mestiere bancari nel mediterraneo occidentale (II-IV d.C.), en Società romana e impero tardoantico, Giardina, Andrea (ed.), (Roma-Bari, 1986), pp. 601-615 y 814-818; ÉL mismo, Huit questions pour une histoire financiére de l'antiquité tardive, en Atti dell'Accademia romanistica costantiniana: XII convegno internazionale sotto l'alto patronato del Presidente della Republica: in onore di Manlio Sargenti (Napoli, 1998), pp. 53-63; BOGAERT, Raymond, Banques et banquiers dans les citès grecques, (Leyde, 1968), pp. 31-33; PetruCCI, Aldo, Persistenza di negozi bancari nelle fonti giuridiche, en Atti dell'Accademia romanistica costantiniana: XII convegno internazionale sotto l'alto patronato del Presidente della Republica: in onore di Manlio Sargenti (Napoli, 1998), pp. 223-250.

${ }^{52}$ A mi juicio, desaparecido el receptum argentarii y recuperada ya la actividad comercial y bancaria, el constitutum debiti pudo haberse alejado del modo en que había sido configurado en el Derecho romano clásico. Podría haberse admitido, así, en este ámbito bancario, una modalidad nueva de constituta celebrados indefense, que habría coexistido con la forma tradicional. A este tipo de constituta, que podrían ser similares en sus efectos al receptum, hacen referencia las últimas palabras de la constitución justinianea C. 4,18,2,2: His videlicet, quae argenti distractores et alii negotiatores indefensa constituerint, in sua firmaitate secudnum morem usque adhuc obtienentem durantibus. Hay que pensar que el problema de la referencia que hacía la formula a un debitum constitutum, no sería tal en el procedimiento de cognición extraordinaria. Petrucci, Aldo, Osservazioni in tema di legislazione giustinianea sul receptum argentarii e sul'antiphonesis, en Fides, Humanitas, Ius. Studii in onore di Luigi Labruna, Cascione, Cossimo y Masi Doria, Carla (eds.), (Napoli, 2007), VI, pp. 4219-4256. Sobre las modificaciones jurídicas de las actividades bancarias, y las garantías en general, véase Díaz BAUTISTA, Antonio, Estudios sobre la banca bizantina, cit. (n. 42), pp. 23-35; 39; 60 ss.; 106 ss.; 113 ss.; 123 y 133 ss.; ÉL MISMO, Notas sobre el aseguramiento de obligaciones en la legislación justinianea, en AHDE., 50 (1980), pp. 683-698; ÉL MISMO, Les garanties bancaires dans la legislation de Justinien, en RIDA., 29 (1982), pp. 165-191.

53 Parece probable que la Constitución C. 4,18,2 esté relacionada con las medidas 
ció una garantía abstracta, que aparece aludida en las Novelas con el nombre de cathará antiphónesis ${ }^{54}$. El edicto 9 justinianeo alude a la celebración de este tipo de negocios en la práctica habitual de los banqueros bizantinos, y refiere, precisamente, las dificultades con que éstos se encontraban en ocasiones para obtener de sus clientes el reembolso de lo que habían pagado a sus acreedores como garantes.

Con estas catharai antiphoneseis el banquero se comprometía a pagar una deuda de un cliente en un plazo fijado, y solía recoger su compromiso en un escrito que entregaba al acreedor. El cliente, por el contrario, no siempre registraba por escrito la orden dada a su banquero y, una vez que éste se comprometía con el acreedor al pago, parece haberse dado la costumbre de que éste remitiera al deudor los documentos que registraban su deuda. Así las cosas, el banquero, sin orden escrita y sin documentos que probasen la existencia de la deuda principal pagada por él, encontraba dificultades para actuar contra el cliente en vía de regreso. Por eso la corporación de banqueros había pedido al emperador que se les reconociese la posibilidad de reclamar a sus clientes, sin que estos pudiesen discutir si el pago realizado correspondía o no a una deuda existente. Una especie de regreso abstracto, que Justiniano les reconoce en este edicto 9, aunque solo en determinadas condiciones, esto es, cuando la orden del cliente se recoge por escrito, o cuando había mediado oposición del cliente al pago en el plazo de dos meses.

legislativas justinianeas relacionadas con el proceso compilador. Ha sido identificada como una de aquellas constituciones ad commodum propositi operis pertinentes [...] quibus maximus antiquarum supervacua prolixitate liberum atque enucleatam in nostris institutionibus et digestis reddidimus (Cordi, 1). La condena de la abstracción del receptum que aparece en la constitución justinianea del 531, que se está refiriendo a un negocio jurídico obsoleto, tiene mayor sentido en este contexto, esto es, en el seno de los trabajos de selección y sistematización del material a compilar. En cambio, la última parte de la misma constitución, en la que se ratifica la validez de los constituta celebrados indefense, tendría, según los estudiosos, más relación con la práctica. Sobre este último extremo véase la nota anterior. Sobre el proceso compilador y este tipo de medidas y las denominadas Quinquaginta decisiones, véase De FransCisCI, Pietro, Nuovi studi intorno alla legislazione giustinianea durante la compilazione delle Pandette, en BIDR., 19 (1907), 22 (1910), 23 (1915); ARCHI, Gian Gualberto, Contributi alla critica del Corpus Iuris II. Riforme giustinianee in tema di garanzie personali, en Scritti di Diritto romano, III. Studi di Diritto posclassico e giustinianeo (Milano, 1981), anteriormente publicado en BIDR., 65 (1962), pp. 281 ss.; AstuTI, Guido, Il costituto di debito cit. (n. 18), II, pp. 281; FreZZA, Paolo, Le garanzie delle obbligazioni, cit. (n. 17), pp. 282 ss.; WEBER, Halcyon, A Hypothesis regarding Justinian;s decisiones and the Digest, en Roman Legal Tradition, 11 (2015), pp. 42-117; VARVARO, Mario, Contributo allo studio delle Quinquaginta Decisiones, en AUPA., 44 (2000), pp. 359-519; Russo RUGGIERI, Carmela, Ancora qualche riflessione sulla politica legislativa di Giustiniano in riguardo ai iura al tempo del Novus Codex, en AUPA., 57 (2014), pp. 153-176.

${ }^{4}$ Díaz Bautista entiende que este tipo de garantía bancaria griega se corresponde casi totalmente con el receptum argentarii clásico. Sin embargo, además de las diferencias importantes que él mismo señala, parece que las fuentes suelen identificar el término antiphónesis con el de constitutum. Por ello, creo más probable que la cathará antiphónesis fuera una modalidad de constitutum y no una recuperación o versión griega/helenística del receptum argentarii. Véase DíAZ BAUTISTA, Antonio, Estudios sobre la banca bizantina, cit. (n. 42), pp. 168 ss.; AstuTi, Guido, Il costituto di debito, cit. (n. 18), II, pp. 294-295; PARTSCH, Joseph, Der ediktale Garantievertrag durch receptum, cit. (n. 18), pp. 417 ss. Sobre la traducción del término antiphónesis en el De Actionibus, véase recientemente la traducción española de Rodríguez MarTín, José-Domingo, El Tratado De Actionibus y sus apéndices (Santiago de Compostela, 2016), pp. 65, n. 187 y 174 y s. 


\section{LAS MODERNAS GARANTÍAS INDEPENDIENTES. A MODO}

DE REFLEXIÓN

Las garantías independientes, llamadas así por crear entre el acreedor y el garante un vínculo autónomo o independiente del de la obligación garantizada o principal $^{55}$, se presentan habitualmente como un fenómeno jurídico de aparición reciente, pues se justifican como respuesta a las necesidades del comercio internacional posterior a la primera crisis del petróleo ${ }^{56}$. Su nacimiento se sitúa en el inicio de los años setenta del siglo XX, cuando se produjo una cierta recesión de las economías desarrolladas y un auge de las de los países productores de petróleo, que comenzaron a requerir infraestructuras para su progresiva industrialización ${ }^{57}$. Los proyectos a realizar en estos nuevos países en desarrollo, caracterizados por su gran envergadura económica y técnica, y su largo y costoso período de ejecución, hacían conveniente que las constructoras internacionales asumiesen garantías efectivas sobre el cumplimiento de sus prestaciones; unas garantías que no se alcanzaban satisfactoriamente con las fianzas tradicionales ni con el más n o v e d o s o contrato de crédito documentario, que funcionaba en realidad como un mecanismo de pago ${ }^{58}$.

55 Reciben también otras denominaciones semejantes, como garantías autónomas, no accesorias, a demanda o primera demanda, a primer requerimiento, a primera solicitud, abstractas, y también, de forma más imprecisa, garantías automáticas y bancarias.

56 San Juan Crucelaegui, Javier, Contratos para la financiación y garantía del comercio internacional (Pamplona, 2008), pp. 390 ss.; Bertrams, Roeland, Bank Guarantees in International Trade (2a edición, Paris-New York, 1996), p. 1 ss.; Ellinger, Peter y Neo, Dora, The Law and Practice of Documentary Letters of credit (Oxford and Portland, Oregon, 2010), pp. 303 ss.

57 Un antecedente de este tipo de garantías parece haber sido ya las denominadas standby letters of credit, emitidas por los bancos estadounidenses en los años sesenta y setenta en su propio mercado nacional. Las entidades bancarias norteamericanas tenían prohibido actuar como garantes (Act for the protection of the Bank Depositors, 1870) y su modo de soslayar tal prohibición fue emitiendo cartas de crédito en espera, esto es, créditos documentarios cuya ejecución quedaba supeditada a que el deudor principal no cumpliera previamente con su obligación de pago. Sobre el origen de las garantías independientes véanse ElLINGER, Peter y NeO, Dora, cit. (n. 56), pp. 5-6; SAN Juan CruCElaegui, Javier, cit. (n. 56), p. 101; Marimón Durá, Rafael, La garantía independiente o a primer requerimiento, en CUÑAT EDO, Vicente y BALLARÍN HernÁndeZ, Rafael (eds.), Estudios sobre Jurisprudencia Bancaria (2a edición, Pamplona, 2002), pp. 481 s.; AlCALÁ DÍAZ, María Ángeles, Función económica y naturaleza jurídica de las garantías bancarias a primera demanda, en Alonso UReba, Alberto y Martínez SimanCAS, Alberto (eds.), Instituciones del Mercado Financiero (Madrid, 1999), pp. 1791 ss.; FERnÁNDEZ Masiá, Enrique, Las garantías bancarias en el comercio internacional, en Boletin Mexicano de Derecho Comparado, 139 (2014), pp. 105 ss.

${ }^{58}$ El contrato de crédito documentario es en realidad un compromiso de pago, cuyo emisor suele ser un banco y su beneficiario el vendedor de una transacción comercial internacional en la que el cliente del banco (ordenante de la operación) es habitualmente el comprador. Lo característico del contrato es que el banco asume este pago como una obligación propia, de modo que las expectativas de cobro del vendedor se ven notablemente reforzadas, por contar a partir de entonces con un deudor adicional y de mayor solvencia que el primero. El banco debe pagar al beneficiario en el momento en que le entregue un conjunto de documentos previamente acordados, sin esperar a que el comprador reciba la mercancía, la examine y declare 
Desde entonces, el uso de esta modalidad de garantía ha ido en aumento en el ámbito del comercio internacional, que demanda, por sus propias características, una protección reforzada de las expectativas contractuales ${ }^{59}$, y se ha extendido también al mercado interno de los países que, en ocasiones, prefieren que la relación entre el garante y el acreedor permanezca independiente de la que existe entre éste y el deudor principal ${ }^{60}$.

En estos presupuestos, esto es, el origen reciente, el ámbito de aplicación principalmente internacional y el régimen jurídico de protección acentuada del acreedor, suele justificarse la ausencia de regulación jurídica específica de estas garantías en el ordenamiento español ${ }^{61}$, así como también que la doctrina y la jurisprudencia las hayan aceptado de forma paulatina y no unánime ${ }^{62}$. Las reticencias iniciales se

su conformidad con la misma. Sobre el momento de aparición y posterior evolución del crédito documentario véanse STOUFFLET, Jean, Le crédit documentaire. Étude juridique d'un instrument financier du commerce international (Paris, 1957), pp. 37 ss.; OKITUNUNGU, Mukoie, Le credit documentaire: instrument de paiment et de financement du commerce international (Leuven, 1976), pp. 16 ss. La unificación internacional de las normas relativas al crédito documentario se produjo por primera vez en 1933 gracias a la Cámara de Comercio Internacional, que aprobó los llamados "Usos y reglas uniformes relativos a los créditos documentarios". Dichas reglas han sufrido diversas modificaciones hasta su última versión, que entró en vigor el día 1 de julio del año 2007, y se conocen internacionalmente como Uniform Customs and Practice for Documentary Credits (UCP 600). Sobre este proceso de elaboración y su evolución, véase Martínez Montenegro, Isnel, El crédito documentario: ¿mecanismo o garantía de pago según la normativa UCP 600?, en Revista Chilena de Derecho y Ciencia Politica, 4 (2013), p. 51 . Acerca de la diferencia entre este contrato y las garantías independientes, véase, por ejemplo, DíAZ MORENO, Alberto, Reglamentación uniforme sobre los contratos de garantía: la labor de la CCI y de UNCITRAL, en Angulo Rodríguez, Luis, CAmacho de los Ríos, Javier y Hoyos Elizalde, Carlos (eds.), Las tendencias actuales de los contratos de garantía, (Barcelona, 2005), pp. 106117; Busto Lago, José Manuel, Las garantías personales atípicas en el ordenamiento jurídico español. Configuración jurídica de las garantías 'a primer requerimiento' y autónomas (Pamplona, 2006), pp. 108 ss.; y MARIMÓn DurÁ, Rafael, cit. (n. 57), pp. 505 ss. No obstante, confróntese Bustillo SÁiz, María del Mar, Sobre la atipicidad de las garantías a primera demanda y del seguro de caución (Granada, 2014), p. 68.

${ }_{59}$ Resulta evidente que las transacciones comerciales internacionales, indispensables hoy en el crecimiento económico de un país, generan riesgos de especial entidad para los contratantes. El carácter azaroso de toda operación comercial se acentúa por la distancia que existe entre las partes, que les hace difícil valorar su solvencia mutua; por el elevado importe que suelen tener las inversiones realizadas, que, a su vez, generan costes de financiación considerables; o por la complejidad de las relaciones jurídicas que se establecen entre sujetos de naciones y sistemas normativos diferentes. Eventualidades como éstas explican que los actores del comercio internacional hayan tratado siempre de asegurar de la forma más efectiva posible los pagos y las prestaciones que hubieran acordado, y justifica que se hayan creado con este fin algunas figuras jurídicas peculiares. Véase, SAn JuAn Crucelaegui, Javier, cit. (n. 56), pp. 31-39.

60 Esta modalidad de garantías ha sido demandada especialmente en el ámbito de la contratación de las Administraciones públicas.

${ }^{61}$ Existen, no obstante, algunas referencias normativas a las garantías independientes en diversas disposiciones de carácter sectorial. Véase SERRANO BARQUÉ, Ricard, Las garantías autónomas a primera demanda, Treball fi de Grau, Universidad de Lleida, 19 de junio de 2015, pp. 42 ss. (Disponible en http://repositori.udl.cat/handle/10459.1/49217).

${ }^{62}$ Acerca de la acogida de las garantías independientes en otros países como Alemania, Suiza, Holanda, Bélgica, Italia y Francia, véase SAN JuAN CruCELAEgui, Javier, cit. (n. 56), pp. 407 ss. 
debían a ciertos problemas para determinar la exacta naturaleza jurídica de estas garantías independientes. Se señalaba la dificultad para identificar su causa, por ser la obligación del garante independiente de la obligación del deudor ${ }^{63}$, y se observaban asimismo impedimentos para su incardinación dogmática más allá de la figura de la fianza ${ }^{64}$. A día de hoy puede decirse que el primer problema, la cuestión sobre la falta de causa de las garantías independientes, está en buena medida superado. El segundo problema, esto es, el de la naturaleza jurídica de estos contratos, fue afrontado de forma general en la STS. de España de 27 de

Señala San Juan que los sistemas jurídicos del Common Law, que conocían el llamado Contract of Indemnity y que habían también aceptado sin mayor problema los llamados Stand-by letters of credit, una modalidad de crédito documentario que sólo puede ejecutarse ante el incumplimiento del deudor, aceptaron más fácilmente este tipo de garantía independiente. Sobre la regulación de estas garantías en los países Iberoamericanos, véase Clavero ArÉvalo, Manuel et alii (eds.), Las garantías a primer requerimiento (Garantías a primera demanda) (Madrid, 1996). Sobre la normativa de carácter internacional, debe señalarse que las reglas uniformes para las garantías a primer requerimiento (Uniform Rules for Demand Guarantees) se elaboraron por primera vez, por la misma Cámara de Comercio Internacional, en 1978 (URCG 325), fueron revisadas en 1992 (URDG 458) y su última versión ha sido aprobada en 2010 (URDG 758). Acerca de la reglamentación uniforme anterior al 2010 véase DíAz Moreno, Alberto, cit. (n. 58), pp. 103-121.

${ }^{63}$ La figura de contratos abstractos no tiene cabida en el Derecho español (art. 1261 CC) en el que se presume, además, la existencia de causa cuando ésta no se exprese, salvo que se pruebe lo contrario (art. 1277 CC). Lo que se produce en estos casos es una inversión de la carga de la prueba, puesto que aquí debe ser el deudor demandado quien pruebe la inexistencia del negocio obligatorio por falta de causa. Véase, DíEz Picazo, Luis, Fundamentos del Derecho Civil Patrimonial (6 ${ }^{a}$ edición, Madrid, 2008), I, pp. 255 ss.; 278 y 280. Señala el civilista que la causa de este tipo de negocios es, precisamente, la garantía: el carácter de indebido que puede tener el pago si la obligación garantizada no existiera, es una prueba de este carácter causal. Véase también, Díez Picazo, Luis, Fundamentos de Derecho Civil Patrimonial (3a edición, Madrid, 1993), II, p. 464. De una causa extrínseca habla Morales Moreno (una situación jurídica anterior), véase, Morales Moreno, Antonio Manuel, Causa (Derecho Civil), en Enciclopedia Jurídica Básica (Madrid, 1995), I, pp. 959 y 960. En desacuerdo con Díez Picazo y quizás más en consonancia con Morales, está San Juan, para quien la causa está en el contrato de mandato o comisión mercantil que existe entre el deudor y el garante. Hay que decir también que se habla asimismo de abstracción para hacer referencia a la inoponibilidad de excepciones por parte del garante, pero se trata en este caso de otro problema distinto que tendría que ver con la falta de accesoriedad; se trataría en este caso de una abstracción funcional. Véase SAN JUAN Crucelaegui, Javier, cit. (n. 56), pp. 444 ss.

${ }^{64}$ Así, por ejemplo, STS. de 2 de octubre de 1990 (RJ. 1990, 7464), que interpreta que la inoponibilidad de excepciones supone que la obligación del garante surge nace in duriorem causam respecto a la del deudor principal, yendo en contra de los principios del contrato de fianza. Véase también STS. de 15 de abril de 1991 (RJ. 1991, 2693). Hay también discrepancias acerca de si la obligación del garante surge o no a partir de su declaración unilateral, en la que asume el compromiso del pago. En este punto parece más acorde con nuestro ordenamiento español (artículo 1089 del código civil sobre las fuentes de las obligaciones y falta de obligatoriedad de las promesas de pago antes de ser aceptadas, más allá de las promesas públicas de recompensa, concursos con premio y la emisión de títulos valores), considerar a las garantías independientes como un contrato consensual. Véase Díez Picazo, Luis, cit. (n. 63), II, pp. 464 ss. y pp. 169 y ss. Algunos mercantilistas, por el contrario, prefieren considerar el compromiso del banco como un negocio atípico unilateral y no recepticio, y rechazan que se trate de una mera oferta de contrato que se perfecciona con el silencio o la reclamación del beneficiario; véase SAN JUAN Crucelaegui, Javier, cit. (n. 56), p. 287. 
octubre de 1992, que definió los aspectos sustanciales de estas garantías en el sistema español ${ }^{65}$. No obstante, no faltan los fallos jurisprudenciales de naturaleza contradictoria $^{66}$, ni han desaparecido totalmente los pronunciamientos doctrinales que niegan el carácter de contrato atípico de las garantías independientes y prefieren reconducirlas al contrato de fianza ${ }^{67}$.

Tras el análisis realizado en este artículo se comprueba, sin embargo, que estamos ante contratos que tienen una tradición jurídica más antigua que la que suele reconocérseles cuando se afirma que han nacido espontáneamente para responder a necesidades prácticas del comercio internacional, y que eran auténticos desconocidos en el ámbito del Derecho hasta épocas recientes ${ }^{68}$. Ya en el Derecho romano clásico, como se ha visto, existió una garantía bancaria denominada receptum argentarii con la que el garante argentarius se comprometía a pagar al acreedor de uno de sus clientes sin poder oponer a éste, llegado el caso, ningún tipo de excepción derivada de la obligación garantizada ${ }^{69}$. En una constitución imperial de Justiniano se lee expresamente que el garante ex recepto podía ser reclamado por el acreedor sin defensa alguna, incluso en los casos en los que la deuda del

${ }^{65}$ La línea seguida por esta sentencia se confirma con muchas otras que consideran que las garantías independientes no son una modalidad de fianza puesto que las normas fijadas en el código civil sobre su accesoriedad son típicamente imperativas, y por tanto, si el contrato se aparta de ellas, escapa también a su consideración de fianza. Lo que permite el reconocimiento de este tipo de garantías, que serían por tanto atípicas, sería el reconocimiento de la libertad contractual consagrada en el art. 1255 del código civil. Véase SAN JUAN CruCELAEGUi, Javier, cit. (n. 56), pp. 405 y 431, y todas las sentencias allí reseñadas.

66 Sobre la evolución de la posición jurisprudencial española respecto al crédito documentario, y las garantías independientes véase, SAN JuAN CRUCELAEGUI, Javier, cit. (n. 56), pp. 276 ss, y especialmente n. 66; Serrano Barqué, Ricard, cit. (n. 61), pp. 17 ss.; SÁnCHeZCALERO GUILARTE, Juan, La configuración jurisprudencial de las garantías a primer requerimiento, en Revista de Derecho Bancario y Bursátil, 136 (2014).

${ }^{67}$ Algunos autores, como Carrasco Perera, niegan que las garantías a demanda sean negocios atípicos y se apoyan en el argumento de que la regulación del código civil español constituye una especie de derecho común cuyas normas, de carácter dispositivo, permiten a las partes la introducción de modificaciones y la creación de distintas clases de fianzas. Critica el civilista el "gusto desmesurado por la atipicidad contractual" y "la precomprensión -agudizada entre nuestros autores mercantilistas- de que toda manifestación nueva del tráfico comercial requiere un tipo contractual nuevo". Para este autor "estaríamos, pues, ante una diversidad de tipos de fianza en función de la voluntad de las partes, pero no ante figuras atípicas”. Véase, CARRASCO Perera, Ángel, Fianza, accesoriedad y contrato de garantía (Las Rozas, 1992), pp. 2 ss. y passim. Sin embargo, la opinión más generalizada considera que las garantías independientes presentan tantas dificultades para encajar en el molde de la fianza típica tradicional que, de ser integradas en él, se produciría una desnaturalización de este contrato por presentarlo con unos contornos excesivamente difusos. Véase San JuAn Crucelaegui, Javier, cit. (n. 56), p. 403: "reconducir e insertar la figura de las garantías independientes y otras obligaciones fideiusorias en el tipo de la fianza, a semejanza de la doctrina alemana e italiana, implica privar prácticamente de cualquier rasgo diferenciativo a la fianza, pues ésta quedaría construida de forma tan amplia que sería muy difícil la más mínima precisión de sus contornos conceptuales”.

${ }^{68}$ Véase BerTrams, Roeland, cit. (n. 56), p 3: "The modern independent guarantee originated from practice and the concept, as it functions today, was unknown in Law".

69 Véase Rodríguez GonzÁlez, Ana M., El 'receptum argentarii' en el Derecho romano clásico. Una propuesta de análisis (Madrid, 2004). 
cliente no fuera realmente debida ${ }^{70}$. Una garantía bancaria que tuvo como heredera en el Derecho bizantino a una figura similar denominada cathará antiphónesis ${ }^{71}$.

De los textos analizados se recaba, además, que las discrepancias doctrinales actuales acerca de si las garantías independientes son o no un contrato autónomo distinto de la fianza (discrepancias que guardan relación directa con el debate sobre si la fianza es, por naturaleza, esencialmente accesoria o no), encuentran justificación en una noción de fianza y de accesoriedad ajenas al Derecho romano, y que, según los estudiosos, aparecen por primera vez en los años previos a la codificación del Derecho civil en Europa. No son las fuentes romanas, sino Pothier en su Traité des obligations (1761), el primero que afirma que la accesoriedad era una característica esencial de la fianza, más aún, el elemento clave que la diferenciaba del resto de formas de garantía ${ }^{72}$. A modo de recapitulación podríamos decir que, aunque los textos relativos a la sponsio, fidepromissio y fideiussio hacen referencia a una accesio respecto a la obligación principal, ésta no indica una dependencia funcional de la garantía respecto a la obligación principal, como se concibe, por ejemplo, en el Derecho civil español.

Por todo ello, afirmar la atipicidad de las garantías independientes actuales no debe considerarse como una afirmación caprichosa para dotar de individualidad a negocios jurídicos que podrían encuadrase en los ya existentes, como se ha afirmado por algún civilista ${ }^{73}$. No es el afán de crear negocios jurídicos nuevos, atribuido en ocasiones a los mercantilistas, lo que dota a este tipo de contratos de garantía de una entidad propia. Como se ha visto, ni son totalmente nuevos ni deben configurarse a partir de la normativa prevista para la fianza, pues se presentan con características definidas y propias ya en la tradición jurídica.

${ }^{70}$ C. $4,18,2$.

${ }^{11}$ Véase Díaz Bautista, Antonio, Estudios sobre la banca Bizantina, cit. (n. 42), p. 168 ss.

${ }^{72}$ El jurista francés explica que, debido al carácter accesorio de la fianza, el fiador entra verdaderamente a formar parte de la obligación que garantiza. En su construcción doctrinal, es la accesoriedad lo que verdaderamente explica los efectos de la fianza (el fiador solo puede obligarse a la prestación de la misma cosa que el deudor; la obligación de garantía se extingue al extinguirse la obligación principal; el garante puede oponer al acreedor las mismas excepciones que podría interponer también el deudor principal). Y para esta construcción intelectual, utiliza las fuentes romanas, pero ofreciendo de ellas una nueva interpretación capaz de armonizar las diferentes coutumes sobre garantías propias de la tradición jurídica francesa. Véase, POTHIER, Robert Joseph, Traité des obligations (reimpresión de la edición de Thomine de 1891, Paris, 2011), \$\$366-384, pp. 174-188; Mannino subraya además que, a partir de la reflexión de los juristas medievales sobre la causa de las obligaciones, Pothier popone una noción de accesoriedad según la cual la obligación del fiador resulta idéntica a la del deudor, en cuanto que la causa de ambas obligaciones es la misma. Explica además cómo esta perspectiva se acoge en el Code Civile francés, y cómo ha sido considerada por los juristas decimonónicos en Alemania e Italia. Véase ManNINO, Vincenzo, Fideiussione e accessorietà, en VACCA, Letizia, La garanzia nella prospettiva storico-comparatistica, cit. (n. 9), p. 75 ss.

73 Véase, Carrasco Perera, Ángel, Fianza, accesoriedad y contrato de garantía, cit. (n. 67). 


\section{BiBLIOGRAFÍA}

Alcalá Díaz, María Ángeles, Función económica y naturaleza jurídica de las garantías bancarias a primera demanda, en Alonso UREBA, Alberto y Martínez SimAnCAS, Alberto (eds.), Instituciones del Mercado Financiero (Madrid, 1999), pp. 1791 ss.

ANDREAU, Jean, La vie financiére dans le monde romain. Les metiers de manieurs d'argent (IV sicle av. JC-III sicle ap. JC) (Roma, 1987).

- Declino e norte dei mestiere bancari nel mediterraneo occidentale (II-IV d.C.), en Società romana e impero tardoantico, GIARDINA, Andrea (ed.), (Roma-Bari, 1986), pp. 601-615 y 814-818.

- Huit questions pour une histoire financiére de l'antiquité tardive, en Atti dell'Accademia romanistica costantiniana: XII convegno internazionale sotto l'alto patronato del Presidente della Republica: in onore di Manlio Sargenti (Napoli, 1998), pp. 53-63.

ARCHI, Gian Gualberto, Contributi alla critica del Corpus Iuris II. Riforme giustinianee in tema di garanzie personali, en Scritti di Diritto romano, III. Studi di Diritto posclassico e giustinianeo, (Milano, 1981) (anteriormente publicado en BIDR., 65 (1962), pp. 281 ss.

Astutı, Guido, Studi preliminari intorno alla promessa di pagamento I. Il costituto di debito, en Annali della Facultà giuridica dell'Università di Camerino, XI (1937), pp. 83 ss.

- Studi intorno alla promessa di pagamento. Il Costituto di debito (Milano, 1941), II.

Bertrams, Roeland, Bank Guarantees in International Trade, (2a edición, Paris-New York, 1996).

Biondi, Biondo, Sponsio e Stipulatio. Divagazioni intorno alla storia del contratto, dell'obligatio, delle garanzie personali, en BIDR., 65 (1962), p. 105 ss.

BOGAERT, Raymond, Banques et banquiers dans les citès grecques (Leyde, 1968).

BorTolucci, Giovanii, Il mandato di crédito, en BIDR., 27 (1915), pp. 239 ss.

BRIGUGLIO, Filippo, Fideiussoribus succurri solet (Milano, 1999).

Bustillo Sáiz, María del Mar, Sobre la atipicidad de las garantías a primera demanda $y$ del seguro de caución (Granada, 2014).

Busto Lago, José Manuel, Las garantías personales atípicas en el ordenamiento jurídico español. Configuración jurídica de las garantías 'a primer requerimiento' y autónomas (Pamplona, 2006).

CARDILli, Riccardo, Garanzie personali e obbligazione, en Scritti per Alessandro Corbino, Piro, Isabella (ed.), (Roma, 2016), pp. 546 ss.

Carrasco García, Consuelo, Supuestos de hecho de la 'exceptio non numeratae pecuniae' en el derecho romano (Madrid, 2000).

Carrasco Perera, Ángel, Fianza, accesoriedad y contrato de garantía (Las Rozas, 1992).

Carvajal, Patricio I. 'Receptum argentarii'. Nota sobre las garantías bancarias abstractas en el Derecho romano y justinianeo, en Ars boni et Aequi, 1 (2005), pp. 127-148.

Clavero ArÉvalo, Manuel et alii (eds.), Las garantías a primer requerimiento (Garantías a primera demanda) (Madrid,1996).

Chianale, Angelo, voz Fideiussione in Diritto comparato, en Digesto delle Discipline Privatistiche. Sezione Civile (Torino, 1992), VIII, pp. 275 ss.

Collinet, Paul, Études historiques sur le droit de Justinien. Le carattere oriental de l'oeuvrre legislative de Justinien et les destinées des institutions classiques en occident (Paris, 1932), I.

CosTa, Paolo, 'Pecunia constituta': ipotesi interpretative, en SDHI., 77 (2011), pp. 129 ss. 
De Franscisci, Pietro, Nuovi studi intorno alla legislazione giustinianea durante la compilazione delle Pandette, en BIDR., 19 (1907), 22 (1910), 23 (1915).

De Martino, Francesco, voz Fidesiussione (Derecho romano), en NNDI, VII, p. 272 ss.

- Studi sulle garanzie personali, II, Intorno alla Sotria della Sponsio, (Napoli, 1938) ahora en D'Ippolito, Federico (ed.), Diritto, economia e Società nel mondo romano (Napoli, 1995), I, p. 224.

Díaz BAUtista, Antonio, Estudios sobre la banca Bizantina (negocios bancarios en la legislación de Justiniano) (Murcia, 1987).

Díaz Bautista Cremades, Adolfo, Antonio Díaz Bautista y la legislación justinianea, en RIDROM., 12 (2014), pp. 237 ss.

- Notas sobre el aseguramiento de obligaciones en la legislación justinianea, en AHDE., 50 (1980), pp. 683-698.

- Les garanties bancaires dans la legislation de Justinien, en RIDA., 29 (1982), pp. 165-191.

Díaz Moreno, Alberto, Reglamentación uniforme sobre los contratos de garantía: la labor de la CCI y de UNCITRAL, en Angulo Rodríguez, Luis, CamaCho de los Ríos, Javier y Hoyos Elizalde, Carlos (eds.), Las tendencias actuales de los contratos de garantía, (Barcelona, 2005), pp. 106-117.

Díez Picazo, Luis, Fundamentos del Derecho Civil Patrimonial, I, (6ª edición, Madrid, 2008), I.

- Fundamentos de Derecho Civil Patrimonial (3a edición, Madrid, 1993), II.

Ellinger, Peter y Neo, Dora, The Law and Practice of Documentary Letters of credit (Oxford and Portland, Oregon, 2010).

FASOLINO, Francesco, Sulle tecniche negoziali bancarie: il 'receptum argentarii', en Labeo, 46 (2000), pp. 186-188.

FERnÁNDEZ MASIÁ, Enrique, Las garantías bancarias en el comercio internacional, en Boletín Mexicano de Derecho Comparado, 139 (2014), pp.105 ss.

Frezza, Paolo, Le garanzie dell obbligazioni. Corso di Diritto romano, I. Le garanzie personali, (Milano, 1962).

González-Palenzuela, M .Teresa, El mandatum pecuniae credendae en el Derecho romano: de instrumento para la promoción del crédito a instrumento de garantía, en Revista General de Derecho Romano, 25 (2015).

Guarino, Antonio, Mandatum credendi (Napoli, 1982).

LA Rosa, Franca, Il formalismo del pretore: 'constituta' e 'recepta', en Labeo, 43 (1997), pp. 202-224.

- La pressione degli argentarii e la reforma giustinianea del constitutum debiti (C.4,18,2), en Nozione, formazione e interpretazione del diritto: dall'età romana alle esperienze moderne: ricerche deidcate al profesor Filippo Gallo (Napoli, 1997), p. 446 ss.

Lenel, Otto, Das 'Edictum Perpetuum'. Ein Versuch zu seiner Wiederherstellung, (reimpresión de la $3^{a}$ edición de Leipzig de 1927, Darmstadt, 1985).

- Palingenesia Iuris civilis, (reimpresión de la edición de Leipzig 1889, Graz, 1960).

- Beiträge zur Kunde des Esdicts und der Edictcommentare, en ZSS., 1 (1881), pp. 62-71.

LÓPEZ AMOR, Mercedes, Receptum argentarii, receptum nautarum, cauuponum, stabulariorum, en Derecho romano de obligaciones, Homenaje al Profesor José Luis Murga Gener (Madrid,1994), pp. 721-728. 
LUCHETTI, Giovanni, Banche, banchieri e contratti bancari nella legislazione giustinianea, en BIDR., 94-95 (1991-1992), pp. 448-472.

Magdelain, André, Le consensualisme dans l'édit du preteur (Paris, 1958).

Mannino, Vincenzo, Fideiussione e accessorietà, en VACCA, Letizia, La garanzia nella prospettiva storico-comparatistica, V Congresso Internazionale ARISTEC, Salisburgo, 13-15 settembre 2001 (Torino, 2003), p. 64 ss.

- L'estensione al garante delle eccezioni del debitore principale nel diritto romano classico, (Torino, 1992).

- Garanzie dell'obbligazione, en Digesto delle discipline privatistiche. Sezione Civile (Torino, 1992), VIII, p. 617 ss.

Mantovani, Dario, Le formule del proceso privato romano per la didattica delle instituzioni di diritto romano (2a edición, Padova, 1999).

MARIMÓN DURÁ, Rafael, La garantía independiente o a primer requerimiento, en CUNAT Edo, Vicente y Ballarín Hernández, Rafael (eds.), Estudios sobre Jurisprudencia Bancaria (2a edición, Pamplona, 2002), pp. 481 ss.

Martínez Montenegro, Isnel, El crédito documentario: ¿mecanismo o garantía de pago según la normativa UCP 600?, en Revista Chilena de Derecho y Ciencia Política, 4 (2013), p. 51 ss.

MitTeis, Ludwig, Receptum argentarii, en 29 (1908), pp. 479-480.

Morales Moreno, Antonio Manuel, Causa (Derecho Civil), en Enciclopedia Jurídica Básica (Madrid, 1995), I, pp. 959 ss.

OKITUNUNGU, Mukoie, Le credit documentaire: instrument de paiment et de financement du commerce international (Leuven, 1976).

ParTSCH, Joseph, Der ediktale Garantievertrag durch 'receptum', en ZSS., 29 (1908), pp. 403-428.

Petrucci, Aldo, 'Mensam exercere'. Studi sull'impresa finanziaria romana (II secolo a C-metà del III secolo d.C.) (Napoli, 1991).

- Persistenza di negozi bancari nelle fonti giuridiche, en Atti dell'Accademia romanistica costantiniana: XII convegno internazionale sotto l'alto patronato del Presidente della Republica: in onore di Manlio Sargenti (Napoli, 1998), pp. 223-250.

- Osservazioni in tema di legislazione giustinianea sul receptum argentarii e sul'antiphonesis, en Fides, Humanitas, Ius. Studii in onore di Luigi Labruna, CasCiOne, Cossimo y Masi Doria, Carla (eds.), (Napoli, 2007), VI, pp. 4219-4256.

Platschek, Johannes, Das Edikt de Pecunia Constituta. Die römische Erfülungszusage und ihre Einbettung in den hellenistischen Kreditverkehr (München, 2013).

PothiER, Robert Joseph, Traité des obligations (reimpresión de la edición de Thomine de 1891, Paris, 2011).

RICART, Encarnació, 'Constitutum debiti' y 'solutionis causa adiectus', en Revista de la Facultad de Derecho de la Universidad Complutense, número monográfico en homenaje al Profesor D. Juan Antonio Arias Bonet, 16 (1990), pp. 241 ss.

- Perfil del 'constitutum debiti', en Seminarios Complutenses de Derecho romano, III (1991), pp. 135 ss; 'Constitutum debiti', en Derecho romano de obligaciones. Homenaje al Profesor José Luis Murga Gener (Madrid, 1994), pp. 695 ss.

Rodríguez GonzÁlez, Ana M., El 'receptum argentarii' en el Derecho romano clásico. Una propuesta de análisis (Madrid, 2004).

Rodríguez Martín, José-Domingo, El Tratado De Actionibus y sus apéndices (Santiago de Compostela, 2016).

Rossello, Adolfo, Receptum argentariorum, en $A G$., 45 (1890), pp. 1-83. 
Russo RugGiERI, Carmela, Ancora qualche riflessione sulla politica legislativa di Giustiniano in riguardo ai iura al tempo del Novus Codex, en AUPA., 57 (2014), pp. 153-176.

San Juan Crucelaegui, Javier, Contratos para la financiación y garantía del comercio internacional (Pamplona, 2008).

SÁnChez-CAlero Guilarte, Juan, La configuración jurisprudencial de las garantías a primer requerimiento, en Revista de Derecho Bancario y Bursátil, 136 (2014).

SEGRÉ, Gino, In materia di garanzie personali, en Bollettino dell'stituto di diritto romano, 42 (N.S.1), ahora en, Scritti vari di diritto romano (Torino, 1942), pp. 482 ss.

SERAFINI, Enrico, Appunti sul receptum argentariorum, en AG., 45 (1890), pp. 553-559.

SERRANO BARQUÉ, Ricard, Las garantías autónomas a primera demanda, Treball fi de Grau, Universidad de Lleida, 19 de junio de 2015, pp. 42 ss (Disponible en http:// repositori.udl.cat/handle/10459.1/49217).

STOUFFLET, Jean, Le crédit documentaire. Étude juridique d'un instrument financier $d u$ commerce international (Paris, 1957).

Talamanca, Mario, voz Fidesiussione (Storia), en ED., XVII, (Milano, 1958), pp. 322 ss.

- L'accessorietà della garenzia fideiussoria. Dall'esperienza romana alle codificazioni moderne (considerazioni finali), en VACCA, Letizia (ed.), La garanzia nella prospettiva storico-comparatistica, V Congresso Internazionale ARISTEC, Salisburgo, 13-15 settembre 2001 (Torino, 2003), p. 151.

Torrent Ruiz, Armando, Accesoriedad de las garantías personales y 'beneficium excussionis', en García Sánchez, Justo, De la Rosa Díaz, Pelayo y Torrent Ruiz, Armando (eds.), Estudios Jurídicos 'in memoriam' del Profesor Alfredo Calonge (Salamanca, 2002), II, pp. 1036 ss.

VArVaro, Mario, Sulla storia dell'editto 'De pecunia constituta', en AUPA., 52 (20072008), pp. 327 ss.

- Contributo allo studio delle Quinquaginta Decisiones, en AUPA., 44 (2000), pp. 359-519.

WaelKens, Laurent, 'Pecunia constituta', un mode de paiment du droit romain, en Memoires de la Societé pour l'Histoire du Droit et des Institutions des Anciens Pays Bourguignons, contois et romands, 65 (2008), pp. 67 ss.

WeBer, Halcyon, A Hypothesis regarding Justinian's decisiones and the Digest, en Roman Legal Tradition, 11 (2015), pp. 42-117.

WENGER, Leopold, 'Receptum argentarii', en PW., vol I. A1, cols. 372-379.

Zoz, Gabriella, Brevi considerazioni sull'assunzione di responsabilità per debito altrui (Trieste, 2011). 
